\title{
Diagnostic Confirmation Code
}

National Cancer Institute

\section{Source}

National Cancer Institute. Diagnostic Confirmation Code. NCI Thesaurus. Code C160894.

The code for the method of cancer diagnostic confirmation. 